\title{
A simple theoretical approach to converging of Myoglobin-Assay with different $\mathrm{pH}$ values
}

\author{
Özgehan Cansu Gülcü, Elvan Üstün \\ Department of Chemistry, Faculty of Art and Science, Ordu University, 52200, Ordu, Turkey \\ elvanustun@odu.edu.tr
}

\begin{abstract}
Many metal carbonyl complexes have been synthesized and analyzed as CO-releasing agents. As in many bioactivity assays, differences between in-vitro and in-vivo studies in Myoglobin Assay have been observed. Adjustment of in-vitro conditions to in-vivo conditions is one way to overcoming this problem. Changing the conditions of each in-vivo assay is not possible considering the available grant, material, and labor facilities. In-silico methods are suitable as they provide better in-vitro conditions before experimental procedures. A method which is easy to employ on a basic computer could be more suitable to observe the assay convergence. In this study, global reactivity descriptors were used as an approach to investigate $\mathrm{pH}$ differences in myoglobin assay. Global reactivity descriptors of the molecules were compared with myoglobin assay results at different $\mathrm{pH}$ values and molecular docking results performed with optimized molecules in different solvents. The following complexes were studied: $\left[\mathrm{Mn}(\mathrm{CO})_{3}(\mathrm{bpy})(\mathrm{L})\right] \mathrm{PF}_{6}$ (bpy: 2,2-bipyridyl, L: benzylbenzimidazole, 4-chlorobenzylbenzimidazole).
\end{abstract}

Keywords: CORMs, DFT/TDDFT, manganese complexes, molecular docking, Myoglobin Assay

\section{Introduction}

Relative affinity of carbon monoxide (CO) for hemoglobin is 210-fold (average) higher than that of oxygen. Binding of carbon monoxide to hemoglobin creates carbonmonoxy-hemoglobin $(\mathrm{CO}-\mathrm{Hb})$ which hinders the adequate transport of oxygen to tissues. $\mathrm{CO}-\mathrm{Hb}$ percentage below $10 \%$ in blood is asymptomatic, while high percentage can cause organ damage and death (Alberto and Motterlini, 2007; Foresti et al., 2008; Romăo et al., 2012; Mann, 2012). Sjöstrand discovered in 1949 that CO is already produced endogenously in human body. In 1968, Tenhunen et al. described endogenous synthesis of $\mathrm{CO}$ in human body during hemoglobin degradation by the heme oxygenase enzyme (Tenhunen, 1968). It has also been determined that, in case of an illness, the amount of $\mathrm{CO}$ is higher than in healthy condition and $\mathrm{CO}$ can affect the healing process (Johnson et al., 2003; Ryter and Otterbein, 2004; Wu and Wang, 2005; Motterlini et al., 2005; Motterlini and Otterbein, 2010). Research on the healing effects of $\mathrm{NO}, \mathrm{CO}$ and $\mathrm{H}_{2} \mathrm{~S}$ molecules in many diseases still continues (Boczkowski et al., 2006; Mann and Motterlini, 2007; Johnson et al., 2007; Farrugia and Szurszewski, 2014).

Since CO is toxic above a certain dose even in therapeutic applications, CO-releasing molecules (CORMs) can help solving the problem. The best candidate for this purpose is the metal carbonyl complexes containing $\mathrm{CO}$ in ligand form. COrelease from a molecule in a certain region of tissue must be regular and manageable as fast or slow release of $\mathrm{CO}$ can lead to problems. Numerous studies on CORMs bioactivity such as antibacterial (Bang et al., 2014), antioxidant (Lamon et al., 2009), anticoagulative (Chlopicki et al., 2012), antiapoptotic (Caumartin et al., 2011), and vasodilatory (Kimberly et al., 2017) can be found in literature. Also, preclinical level studies on CORMs are remarkable (Motterlini et al., 2002; Clark et al., 2003; Foresti et al., 2004; Ryan et al., 2006; Bani-Hani et al., 2006; Niesel et al., 2008; Hasegawa et al., 2010). Most metal carbonyl complexes are sensitive to UV-Visible light used in the modification of metal carbonyl complexes (Hartl et al., 2007). Therefore, certain wavelength of $\mathrm{UV} / \mathrm{V}$ is light is used to trigger CO-release and these CO-releasing molecules are defined as photo-activatable CO-releasing molecules (photoCORMs) (Pfeiffer et al., 2013; Mansour and Ragab, 2019).

The most commonly used method to measure COreleasing properties of a molecule is the Myoglobin Assay (Govender et al., 2013; Smith et al., 2011). In this method, the conversion of deoxy-myoglobin to carbonmonoxy-myoglobin by binding carbon monoxide in buffered medium is followed by spectroscopic methods. During the investigation of the CO-releasing properties of molecules, the solutions are generally buffered to physiological $\mathrm{pH}$ although many organs and tissues in the body have different $\mathrm{pH}$ values (Ji et al., 2016). For example, while $\mathrm{pH}$ in the small and large intestine is between $4-7$, it is between $7-8.5$ in the duodenum, 6 in the 
upper parts of the stomach while it can fall to 1.5 in the lower part of the stomach. Therefore, results obtained from in-vitro measurements performed only at physiological pH cannot be compatible with those from tissue experiments. Motterlini et al. recorded significant changes in the amount and rates of released $\mathrm{CO}$ depending on the $\mathrm{pH}$ value (Motterlini et al., 2002). Similarly, Ji et al. also noted a significant increment in the $\mathrm{CO}$-releasing rate at acidic $\mathrm{pH}$ values ( $\mathrm{Ji}$ et al., 2016). In this case, acidity is a criterion to be evaluated for correct design of future studies. Considering the labor, time and grant needed for research as well as the mostly toxic waste of assays, a practical solution is required.

In this study, CO-releasing activity of manganese carbonyl complexes was analyzed depending on $\mathrm{pH}$ values by both experimental and theoretical methods. CO-releasing properties of previously characterized [ $\mathrm{Mn}(\mathrm{CO})_{3}(2,2-$-bipyridine)(benzylbenzimidazole $)] \mathrm{PF}_{6} \quad$ (1) and $\left[\mathrm{Mn}(\mathrm{CO})_{3}(2,2-\mathrm{bi}-\right.$ pyridine)(4-chlorobenzylbenzimidazole) $\mathrm{PF}_{6} \quad$ (2) (Üstün et al., 2018) were analyzed at $\mathrm{pH}=6.0,7.6$, and 9.0 (Figure 1) using the Myoglobin Assay. To the best of our knowledge, there are no studies analyzing the structural and mechanical effects of $\mathrm{pH}$ on the bioactivity analysis by computational methods. Different solvents were accepted as matrixes for different $\mathrm{pH}$ values. Structural properties of optimized molecules were compared by global reactivity descriptors. Interactions of the selected structures were investigated by molecular docking methods against hemoglobin and myoglobin.

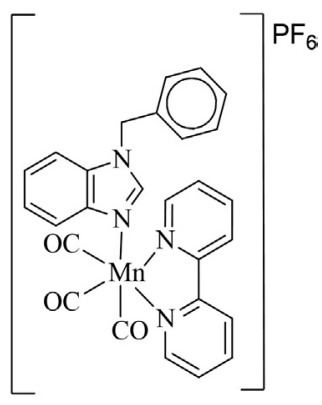

1

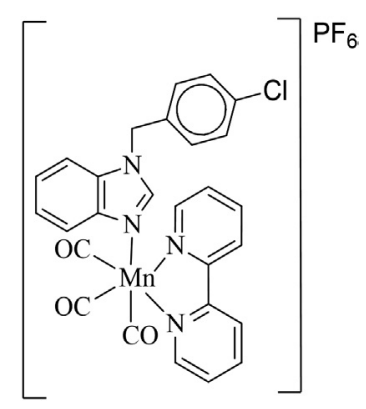

2
Fig. 1. $\left[\mathrm{Mn}(\mathrm{CO})_{3}(\mathrm{bpy})(\mathrm{L})\right] \mathrm{PF}_{6}$ type complexes with benzimidazole derivative ligands.

\section{Result and Discussion}

The complexes were characterized using ${ }^{1} \mathrm{H}$ NMR, ${ }^{13} \mathrm{C}$ NMR, IR, and LC-MS. 1H NMR spectra of 1 showed overlaps because of the aromatic rings present in the complex. However, integration of the spectra of $\mathbf{1}$ was good as expected. NMR multiplets between 8.60-6.92 were assigned to bpy and benzimidazole of $\mathbf{1}$. Single signal at $9.48 \mathrm{ppm}$ also indicates the hydrogen atom on the NCHN part of the molecule. ${ }^{1} \mathrm{H}$ NMR spectra of $\mathbf{2}$ show better splitting and integrations. The doublet at $9.97 \mathrm{ppm}$ can be assigned to two hydrogens on the benzyl part of the molecule. Also, the signal at 8.04 ppm indicates a hydrogen in the benzimidazole part of the ligand. NCHN signals at $145.9 \mathrm{ppm}$ and $156.0 \mathrm{ppm}$ on ${ }^{13} \mathrm{C}$-NMR spectra of the aromatic groups were identical. The benzyl $\mathrm{CH}_{2}$ of benzimidazole deri-

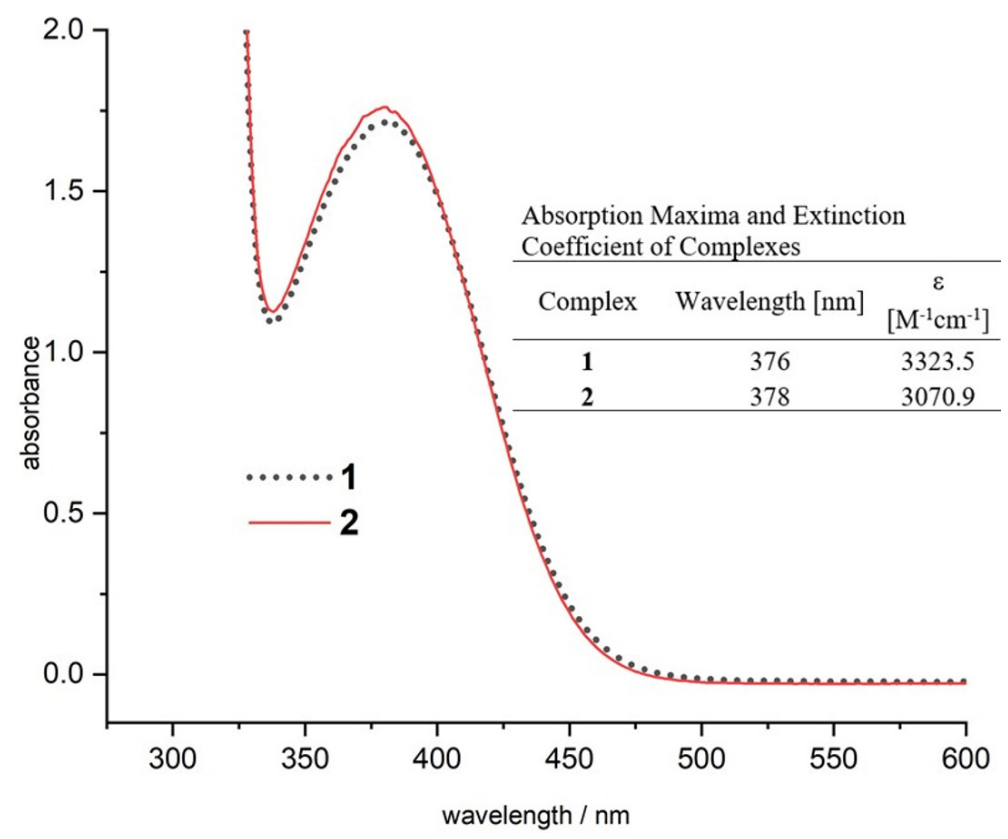

Fig. 2. UV-Vis Spectra and Extinction Coefficients of $\mathbf{1}$ and 2. 
Tab. 1. CO-releasing properties of $\mathbf{1}$ and $\mathbf{2}$ at $\mathrm{pH}=6.0,7.6$, and 9.0.

\begin{tabular}{ccccc}
\hline Molecules & $\mathrm{pH}$ & $\begin{array}{c}\text { Concentration } \\
\text { of MbCO }[\mu \mathrm{M}]\end{array}$ & $\begin{array}{c}\text { Half-life } \\
\mathrm{t}_{1 / 2}[\mathrm{~min}]\end{array}$ & $\begin{array}{c}\text { Equivalent } \\
\text { of CO released }\end{array}$ \\
\hline \multirow{2}{*}{$\mathbf{1}$} & 6.0 & 17.94 & 24.22 & 1.20 \\
& 7.6 & 12.11 & 28.38 & 0.81 \\
\hline \multirow{2}{*}{$\mathbf{2}$} & 9.0 & 16.94 & 23.58 & 0.13 \\
\hline
\end{tabular}

Tab. 2. HOMO and LUMO energies and global reactivity descriptors of $\mathbf{2}$ (in $\mathrm{eV}$ ).

\begin{tabular}{|c|c|c|c|c|c|c|}
\hline & HOMO & LUMO & $x$ & $\eta$ & $\delta$ & $\omega$ \\
\hline Isola & -8.36 & -6.57 & 7.47 & 0.90 & 0.56 & 31.06 \\
\hline Acetic acid & -6.36 & -4.32 & 5.34 & 1.02 & 0.49 & 13.95 \\
\hline Acetone & -5.97 & -3.85 & 4.91 & 1.06 & 0.47 & 11.35 \\
\hline Acetonitrile & -5.90 & -3.76 & 4.83 & 1.07 & 0.47 & 10.88 \\
\hline DCM & -6.19 & -4.11 & 5.15 & 1.04 & 0.48 & 12.76 \\
\hline Dioxane & -7.18 & -5.26 & 6.22 & 0.96 & 0.52 & 20.20 \\
\hline DMF & -5.89 & -3.75 & 4.82 & 1.07 & 0.47 & 10.85 \\
\hline DMSO & -5.88 & -3.73 & 4.80 & 1.07 & 0.47 & 10.74 \\
\hline Ethanol & -5.95 & -3.82 & 4.88 & 1.06 & 0.47 & 11.19 \\
\hline Ethyl acetate & -6.37 & -4.33 & 5.35 & 1.02 & 0.49 & 14.03 \\
\hline Methanol & -5.91 & -3.77 & 4.84 & 1.07 & 0.47 & 10.95 \\
\hline THF & -6.28 & -4.22 & 5.25 & 1.03 & 0.49 & 13.39 \\
\hline Toluene & -7.16 & -5.18 & 6.14 & 0.96 & 0.52 & 19.61 \\
\hline Water & -5.85 & -3.69 & 4.77 & 1.08 & 0.46 & 10.53 \\
\hline
\end{tabular}

vative ligands showed signals at $47.9 \mathrm{ppm}$ and 49.0 ppm for 1 and $\mathbf{2}$, respectively. IR spectra of the molecules were compatible with the Cs point group. Strong CO bands were observed at $2033.0 \mathrm{~cm}^{-1}$, $1944.2 \mathrm{~cm}^{-1}$, $1925.0 \mathrm{~cm}^{-1}$ for $\mathbf{1}$, while CO bands of 2 were recorded at $2040.7 \mathrm{~cm}^{-1}, 1952.0 \mathrm{~cm}^{-1}$, $1921.1 \mathrm{~cm}^{-1}$. The band at $1604.8 \mathrm{~cm}^{-1}$ was assigned to $\mathrm{C}-\mathrm{N}$. LC-MS results of each complex were consistent with expectations. The strongest bands were attributed to $\mathrm{M}-\mathrm{PF}_{6}$ forms of the compounds. The molecules displayed broad maximums at $376 \mathrm{~nm}$ and $378 \mathrm{~nm}$ and the extinction coefficients were calculated according to the Lambert Beer Law.

There are various methods for CO release (Botov et al., 2013; Üstün et al., 2016). Although thermal and enzymatic triggering methods are remarkable, photochemical CO-release is also popular and frequently used. Most metal carbonyl complexes are suitable for this method due to their photoactivity. Many manganese complexes, considered as biocompatible, have been evaluated in various bioactivity studies such as the Myoglobin-Assay (Huber et al., 2012; Chakraborty et al., 2014). The method is based on monitoring deoxy-myoglobin conversion to carbonmonoxy-myoglobin (MbCO) using a UV-Visible Spectrophotometer. While deoxy-myoglobin gives a single maximum at $557 \mathrm{~nm}$; carbonmonoxy-myoglobin gives two maxima at $540 \mathrm{~nm}$ and $577 \mathrm{~nm}$ and thus CO-release becomes observable and measurable. Although body tissues have different $\mathrm{pH}$, the in-vitro medium is usually buffered to the physiological $\mathrm{pH}$ during the COreleasing assay. Therefore, CO-releasing properties of each molecule were measured at $\mathrm{pH}=6.0$, 7.6 and 9.0.

It is clear from Table 1 that the acidity of the environment affects $\mathrm{CO}$-releasing properties of the ligands. Variations in acidity change not only the carbonmonoxy-myoglobin concentration ([MbCO $]$ ) but also its half-life $(\mathrm{t} 1 / 2)$ and the equivalent of released $\mathrm{CO}$ (eq. CO). Our studies were started with the idea that the molecules display a regular change depending on the substituents and acidity variation based on the research of Motterlini et al. (2005) and Ji et al. (2016). However, regular changes were not observed in any of the results. Both carbonmonoxy-myoglobin concentration and the half-life increased with the $\mathrm{pH}$ increment in $\mathbf{2}$ (Figure $\mathrm{S} 1$ ). 
On the other hand, there is no regular change due to $\mathrm{pH}$ change in $\mathbf{1}$. Thus, generalization is not possible and more studies should be performed. Also, differences in CO-releasing values depend on the substitution types recorded.

Structural and frontier orbital analyses were performed after the optimization of both molecules in different solvents. Some calculated bond lengths and angles selected from the optimization results are listed in Table S1. Global reactivity descriptors were used as a calculation method to evaluate relative activities of molecules in electron donating/accepting reactions depending on HOMO and LUMO energies and HOMO-LUMO gaps according to the Koopman Theorem (Koopmans, 1934). The criteria calculated by this theorem can be regarded as a measure of the molecules behavior as Lewis' acids or Lewis' bases. HOMO energy determines the ionization potential of the molecules whereas LUMO energy describes electron affinity. According to the principle of maximum hardness, molecules with high HOMOLUMO gap values are called hard molecules and they show higher stability. Reactivity decreases with the increasing of hardness in case of electron transfer or rearrangement under constant external potential. Molecular softness is the inverse of molecular hardness, and high softness means low stability and high reactivity. Electronegativity $(\chi)$, chemical softness $(\delta)$, and chemical hardness $(\eta)$ values can be determined from Table 2 as a magnitude of reactivity (Serdaroğlu and Şahin, 2019; Roy et al., 1998). While the molecule is the most reactive in water, it is noteworthy that the electrophilicity index $(\omega)$ is the lowest in water.

Molecular docking is an essential tool in in-silico drug research (Özdemir et al., 2020; Tian et al., 2015; Varma et al., 2020). In this study, the CO- releasing activities determined at different $\mathrm{pH}$ values were compared with the theoretical results. In molecular docking analysis, acetic acid as acidic, DMSO as basic and water as neutral environments were used for myoglobin (lnz3) and hemoglobin (6fqf), and isola form was also added. It should be noted that the interaction values calculated for myoglobin and hemoglobin are fairly different from each other. Although no significant difference was noted in the myoglobin interactions of $\mathbf{2}$, the highest binding energy was calculated for the in-water optimized structure. The most obvious result of the myoglobin interactions is the similar molecules' binding orientation. In-acetic acid, 2 interacts with the region containing Leu29, Val68, Thr39, Ile99, His94 and Leu89 amino acids; showing H-bonds with Val67, Val68 and His93, pi-sigma interaction with His64, and alkyl/ pi-alkyl interactions with Lys42, Ile99, Tyr103, Ile107, Leu72, Leu89 and Leu104 (Figure 3). The interactions of $\mathbf{2}$ in water, DMSO and isola form can be seen in Table 3 and Figures S2-S4.

All forms of optimized $\mathbf{2}$ interacted in the same region of myoglobin. Binding constants in acetic acid, DMSO, and in water form of $\mathbf{2}$ against myoglobin were calculated to be $-36.30 \mathrm{~kJ} / \mathrm{mol},-36.68 \mathrm{~kJ} / \mathrm{mol}$ and $-36.76 \mathrm{~kJ} / \mathrm{mol}$, respectively. Although the differences between the results are smaller than expected, they indicate different interactions in different solvents. Differences in the hemoglobin results show the same trend. The most effective result with the binding energy of $-33.12 \mathrm{~kJ} / \mathrm{mol}$ was obtained from the calculations performed for acetic acid. The greatest contribution to the binding energy comes from the H-bonds with Phe41, Phe42, Phe45, Ser44 and His63, while the pi-sigma interaction

Tab. 3. Molecular docking results of $\mathbf{2}$ for myoglobin and hemoglobin targets.

\begin{tabular}{lcc}
\hline Solvent & Bind. Aff. $^{*}$ & Amino Acids** Residue \\
\hline Isola & -36.47 & Myoglobin (1nz3) \\
Acetic acid & -36.30 & Val67, Val68, His93, His64, Leu72, Leu89, Leu 104, Lys42, Ile99, Tyr 103 \\
DMSO & -36.68 & Val67, Val68, His93, His64, Phe43, Leu89, Leu104, Leu72, Ile107, Lys42, Ile99, Tyr 103 \\
Water & -36.76 & Val67, Val68, His93, His64, Leu72, Ile107, Leu89, Leu104, Lys42, Ile99, Tyr103 \\
\hline & & Hemoglobin (6fqf) \\
\hline Isola & -16.03 & Thr84, Asp73, Lys66, Ala70, Leu88 \\
Acetic acid & -33.12 & Phe41, Ser44, Phe42, Phe45, His63, Leu91, Val67, Leu 106, Leu28, Val98 \\
DMSO & -21.90 & Leu106, His63, His92, Leu28, Val67, Ala70, Leu88, Leu141, Lys66 \\
Water & -32.91 & Phe41, Ser44, Phe42, Phe45, His63, Leu96, Leu91, Leu28, Val67, Val98, Leu106 \\
\hline
\end{tabular}

${ }^{*}$ Binding Affinity in $\mathrm{kJ} / \mathrm{mol}$.

${ }^{* *}$ His: Histidine, Val: Valine, Phe: Phenylalanine, Leu: Leucine, Ala: Alanine, Ile: Isoleucine, Lys: Lysine, Tyr: Tyrosine, Ser: Serine. 


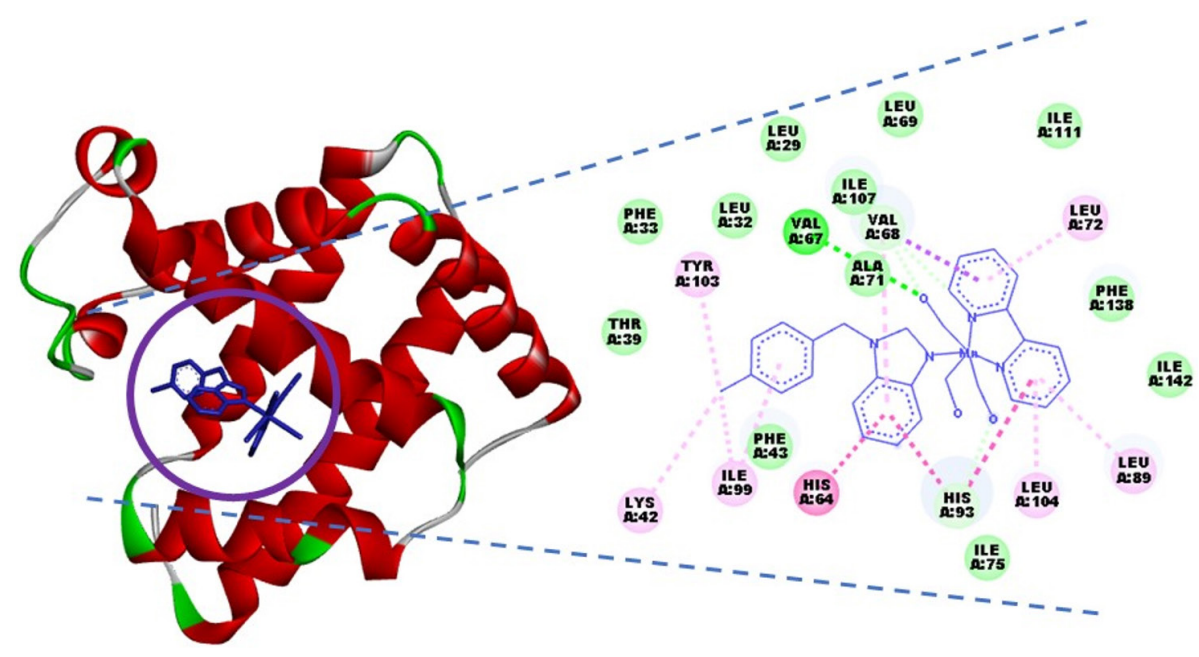

Fig. 3. The best molecular docking pose of 2 optimized in acetic acid with myoglobin crystal structure (dark green and turquoise: H-bonds; green: van der Waals; orange: $\pi$-anion/cation; pink: alkyl and $\pi$-alkyl; yellow: $\pi$-sulfur; fuchsia: $\pi-\pi$ stacked and $\pi-\pi$ T shaped).

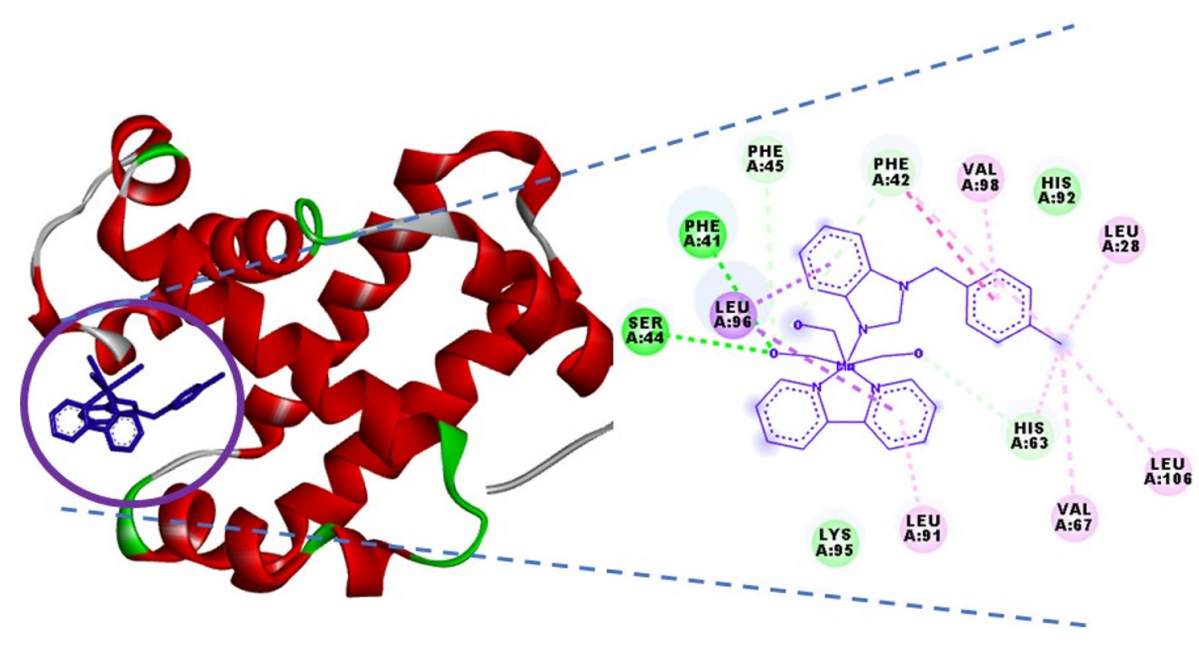

Fig. 4. The best molecular docking pose of 2 optimized in acetic acid with hemoglobin crystal structure (dark green and turquoise: H-bonds; green: van der Waals; orange: $\pi$-anion/cation; pink: alkyl and $\pi$-alkyl; yellow: $\pi$-sulfur; fuchsia: $\pi-\pi$ stacked and $\pi-\pi$ T shaped).

between Leu96 and the cyclic part of benzimidazole is also considerable. Binding constants for isola, DMSO and water form of $\mathbf{2}$ against hemoglobin were recorded to be $-16.03 \mathrm{~kJ} / \mathrm{mol},-21.90 \mathrm{~kJ} / \mathrm{mol}$, and $-32.91 \mathrm{~kJ} / \mathrm{mol}$, respectively. According to these results, the more acidic environment results in higher binding constants. It must be noted that the results obtained with hemoglobin were compatible with the study of Motterlini et al. (2005) and Ji et al (2016). Interaction details can also be analyzed in Table3, Figures 3 and 4, and Figures S5-S7.

\section{Material and Method}

\section{General Remarks}

All reactions were carried out under argon using standard Schlenk and vacuum techniques. Sol- vents were freshly distilled after refluxing over metallic sodium or phosphorous pentoxide for 3-4 days. IR spectra were recorded on solid samples using a Shimadzu IRAffinity-1 ATR spectrometer. Band intensities are marked as strong ( $\mathrm{s}$ ), medium (m), weak (w), or shoulder (sh). NMR spectra were recorded on a Bruker Ultra Shield $300 \mathrm{MHz}$ spectrometer. Chemical shifts $\delta$ in ppm indicated a downfield shift relative to tetramethylsilane (TMS) and were referenced relative to the solvent signals. Coupling constants J are given in Hertz. Absorption spectra were measured using a Shimadzu UV-1800 spectrophotometer equipped with quartz cuvettes $(\mathrm{d}=1 \mathrm{~cm})$. LC-MS was carried out on an Agilent 1100 Series instrument. $\mathrm{pH}$ values of the solutions were measured using an OHAUS Starter2000 pH-meter. All chemicals 
were purchased from Sigma Aldrich and used without further purification.

\section{Synthesis and Characterization}

\section{Synthesis Method}

Complexes $\mathbf{1}$ and $\mathbf{2}$ were synthesized by a similar method. $\mathrm{Mn}(\mathrm{CO})_{3}(\mathrm{bpy}) \mathrm{Br}(100 \mathrm{mg}, 0.267 \mathrm{mmol})$ were added into silver triflate (AgOTf) $(82.2 \mathrm{mg}$, $0.320 \mathrm{mmol})$ solution in acetone $(15 \mathrm{~mL}) . \mathrm{AgBr}$ precipitated and the residuum was filtrated by Celite, the ligands (benzylbenzimidazole for $\mathbf{1}$ and 4-chlorobenzylbenzimidazole for $\mathbf{2}$ were added and stirred for a day at room temperature. Then, $\mathrm{KPF}_{6} /$ methanol solution was added anion exchange after acetone was evaporated. Precipitated yellow/orange product was filtered and washed with cold methanol and diethyl ether. All glassware was wrapped in aluminum foil during the synthesis procedure to be protected from light.

\section{$\left[\mathrm{Mn}(\mathrm{CO})_{3}(\right.$ bpy $)($ benzylbenzimidazole $\left.)\right] P F_{6}(\mathbf{1})$}

${ }^{1} \mathrm{H}$ NMR $\left(300 \mathrm{MHz}, \mathrm{DMSO}-\mathrm{D}_{6}\right): \delta(\mathrm{ppm})=5.36$ $\left(\mathrm{s}, 2 \mathrm{H}, \mathrm{NCH}_{2} \mathrm{C}_{6} \mathrm{H}_{5}\right), 9.48(\mathrm{~s}, 1 \mathrm{H}, \mathrm{NCHN}), 8.60-$ $6.92\left(\mathrm{~m}, 16 \mathrm{H}, \mathrm{NCH}_{2} \mathrm{C}_{6} H_{5}, \mathrm{NC}_{10} H_{8} \mathrm{~N}\right.$ and $\left.\mathrm{N}_{2} \mathrm{C}_{6} H_{5}\right)$. ${ }^{13} \mathrm{C}$ NMR (300 MHz, DMSO-D 6 ): $\delta(\mathrm{ppm})=$ $47.9\left(\mathrm{NCH}_{2} \mathrm{C}_{6} \mathrm{H}_{5}\right), 145.9(\mathrm{NCHN}), 155.0,140.4$, 128.7, 127.8, $127.1\left(\mathrm{~N}_{2} C_{10} \mathrm{H}_{8}\right), 154.8,141.3,135.4$, $133.0 \quad\left(\mathrm{NCH}_{2} C_{6} \mathrm{H}_{5}\right), \quad 128.0, \quad 124.0, \quad 117.1, \quad 112.5$ $\left(\mathrm{N} C_{6} \mathrm{H}_{4} \mathrm{~N}\right)$. LCMS: $\mathrm{m} / \mathrm{z} 499.0\left[\mathrm{M}-\mathrm{PF}_{6}\right]^{+}$. IR $\left(\mathrm{cm}^{-1}\right.$, ATR): $\nu=1442.7,1519.9(\mathrm{~s}, \mathrm{C}-\mathrm{H}), 1604.8(\mathrm{~s}$, C-N), 2033.0, 1944.2, 1925.0 (s, CO).

$\left[\mathrm{Mn}(\mathrm{CO})_{3}(\right.$ bpy)(4-chlorobenzylbenzimidazole) $] P F_{6}(2)$

${ }^{1} \mathrm{H}$ NMR $\left(300 \mathrm{MHz}, \mathrm{DMSO}-\mathrm{D}_{6}\right) \delta(\mathrm{ppm})=5.36(\mathrm{~s}, 2 \mathrm{H}$, $\left.\mathrm{NCH}_{2} \mathrm{C}_{4} \mathrm{H}_{4} \mathrm{Cl}\right), 9.97\left(\mathrm{~d}, \mathrm{~J}=20.5,2 \mathrm{H}, \mathrm{NCH}_{2} \mathrm{C}_{4} H_{4} \mathrm{Cl}\right)$, 7.33-7.29 (m, 4H, $\left.\mathrm{NC}_{6} H_{4} \mathrm{~N}\right), 7.64-7.59(\mathrm{~m}, 1 \mathrm{H}$, $\left.\mathrm{NCH}_{2} \mathrm{C}_{4} H_{4} \mathrm{Cl}\right), 7.87-7.78\left(\mathrm{~m}, 3 \mathrm{H}, \quad \mathrm{NC}_{6} H_{4} \mathrm{~N}\right.$ and $\left.\mathrm{NC}_{10} H_{8} \mathrm{~N}\right), 8.04(\mathrm{~s}, 1 \mathrm{H}, \mathrm{NCHN}), 8.31(\mathrm{t}, \mathrm{J}=18.5$, $\left.2 \mathrm{H}, \mathrm{NC}_{10} H_{8} \mathrm{~N}\right), 8.62\left(\mathrm{~d}, \mathrm{~J}=20.0, \mathrm{NG}_{10} H_{8} \mathrm{~N}\right), 9.50(\mathrm{~d}$, $\left.\mathrm{J}=13.0, \mathrm{NC}_{10} H_{8} \mathrm{~N}\right) .{ }^{13} \mathrm{C} \mathrm{NMR}\left(300 \mathrm{MHz}, \mathrm{CDCl}_{3}\right) \delta$ $(\mathrm{ppm})=49.0\left(\mathrm{NCH}_{2} \mathrm{C}_{6} \mathrm{H}_{4} \mathrm{Cl}\right), 156.0(\mathrm{NCHN}), 154.0$, 140.6, 129.5, 129.4, $128.0\left(\mathrm{~N}_{2} C_{10} \mathrm{H}_{8}\right), 154.0,143.0$, 143.0, 134.6, 134.0, $133.5\left(\mathrm{NCH}_{2} \mathrm{C}_{6} \mathrm{H}_{4} \mathrm{Cl}\right), 125.2$, 125.0, 124.6, 118.5, 112.2 $\left(\mathrm{NC}_{6} \mathrm{H}_{4} \mathrm{~N}\right)$. LCMS: $\mathrm{m} / \mathrm{z}$ $533.0\left[\mathrm{M}-\mathrm{PF}_{6}\right]^{+}$. IR $\left(\mathrm{cm}^{-1}, \mathrm{ATR}\right): \nu=1442.7,1516.0(\mathrm{~s}$, C-H), $1604.8(\mathrm{~s}, \mathrm{C}-\mathrm{N}), 2040.7,1952.0,1921.1(\mathrm{~s}$, $\mathrm{CO})$.

\section{Myoglobin Assay}

Phosphate buffer solutions (0.1 M, pH = 6.0, 7.6, 9.0) for myoglobin and sodium dithionite dilution were prepared and their $\mathrm{pH}$ values were confirmed with a pH-meter to monitor the assay solutions' buffer capacity. Horse muscle myoglobin solution was prepared by dissolving myoglobin from horse skeletal muscle (Sigma Aldrich, M0630) in PBS, separating the insoluble substance, and solution concentrations were confirmed with the absorption band at $557 \mathrm{~nm}\left(\varepsilon=13.8 \mathrm{M}^{-1} \mathrm{~cm}^{-1}\right)$. Myoglobin solution was reduced to deoxy-myoglobin by addition of sodium dithionite solution. Stock solutions of complexes $\mathbf{1}$ and $\mathbf{2}$ were prepared in DMSO. PBS $(0.1 \mathrm{M}, \mathrm{pH}=6.0,7.6,9.0), 100 \mathrm{mM}$ sodium dithionite $(100 \mu \mathrm{L}), 15 \mu \mathrm{M}$ metal carbonyl complex and $60 \mu \mathrm{M}$ myoglobin were incubated in a cuvette in the total volume of $1000 \mu \mathrm{L}$, which was degassed by bubbling with argon in each step of the procedure. Final solution was put perpendicularly in front of the UV lamp in the distance of $5 \mathrm{~cm}$ in a closed cuvette and all the spectra were collected by the Shimadzu UV 1800 UV-Vis Spectrophotometer. Since the molecules have a maximum at $376 \mathrm{~nm}$ (for 1) and $378 \mathrm{~nm}$ (for 2), irradiation was done using a $365 \mathrm{~nm}$ CAMAG UV Lamp in 1-minute intervals until no more differences in carbonmonoxymyoglobin concentration were observed. All irradiation experiments were carried out in triplicate. Solutions were freshly prepared for photoactivation experiments, and all myoglobin assay procedures were performed at room temperature.

\section{DFT Calculation Method}

DFT calculations were carried out with the ORCA version 2.8 using hybrid density BP86 functional combining "exact exchange" with gradient-corrected density and resolution-of-the-identity (RI) approximation, a def2-TZVP/ def2-TZVP/J basis set, tightscf and grid 4 options, and the COSMO solvation model were used for geometry optimizations (Neese, 2009; Weigend and Ahlrichs, 2005; Neese, 2012; Neese, 2006).

\section{Global Reactivity Calculation Method}

Electron affinity (A) and ionization energy (I) were calculated by the Koopmans Theorem with HOMO and LUMO energies (Koopmans, 1934) given by the following equations

$$
\begin{aligned}
& I=-\mathrm{E}_{\text {HOMO }} \\
& A=-\mathrm{E}_{\text {LUMO }}
\end{aligned}
$$

The global reactivity descriptors were calculated with the frontier molecular orbital energies using the equations:

$$
\begin{gathered}
\chi=-\frac{I+A}{2} \\
\eta=\frac{I-A}{2} \\
S=\frac{1}{2 \eta}
\end{gathered}
$$




$$
\omega=\frac{\mu^{2}}{2 \eta}
$$

where $\chi, \eta, S$, and $\omega$, define electronegativity, global hardness, chemical softness, and electrophilicity index, respectively.

\section{Molecular Docking Method}

Molecular docking was performed using AutoDock 4.2. with crystal structure of myoglobin (PDB code: 1nz3) and hemoglobin (PDB code: 6fqf) from RCSB protein data bank (Morris et al., 2009). Water was removed from the proteins and polar hydrogen atoms and Kollman charges were evaluated for target molecules in the docking process (Singh and Kollman, 1984). Gasteiger charges, randomized starting positions, optimizations and torsions were evaluated for the ligand molecules (Bursulaya et al., 2004; Morris et al., 1999). The genetic algorithm population of 150 was used applying the Lamarkian genetic algorithms (BIOVA).

\section{Conclusion}

Dependence of CO-releasing activities of two manganese carbonyl complexes on $\mathrm{pH}$ values was analyzed by both experimental and theoretical methods. The myoglobin-assay solutions showed diverse CO-releasing values at different $\mathrm{pH}$ values. To confirm these experimental results, different solvents were accepted as matrix for different $\mathrm{pH}$ values and the molecules were optimized in different solvents. The global reactivity descriptors confirmed that the solvent options cause different reactivity related to different $\mathrm{HOMO} / \mathrm{LUMO}$ energies. Additionally, interactions of the selected structures with hemoglobin and myoglobin were investigated by molecular docking methods. The myoglobin results confirmed that a more acidic environment ensured stronger interactions. More detailed research on the changes of CO-releasing properties relative to acidity are necessary and new approaches should be studied, e.g. analysis of the CO-release mechanisms, to overcome the problem with in-silico methods.

\section{Acknowledgement}

The support of Scientific and Technological Research Council of Turkey (TÜBİTAK, Project No: 112T320) is gratefully acknowledged.

\section{References}

Alberto R, Motterlini R (2007) Dalton Transactions 17: 1651-1660.

Bang CS, Kruse R, Demirel I, Önnberg A, Söderquist B, Persson K (2014) Microbial Pathogenesis 66: 29-35.
Bani-Hani MG, Greenstein D, Mann BE, Green CJ, Motterlini R (2006) Pharmacological Reports 58: 132-144.

BIOVIA, Dassault Systèmes, Discovery Studio, [4.1.0], San Diego: Dassault Systèmes, [2019].

Boczkowski J, Poderoso JJ, Motterlini R (2006) Trends in Biochemical Sciences 31(11): 614-621.

Botov S, Stamellou E, Romanski S, Guttentag M, Alberto R, Neudörfl J-M, Yard B, Schmalz H-G (2013) Organometallics 13(32): 3587-3594.

Bursulaya BD, Totrov M, Abagyan R, Brooks CL (2004) Journal of Computer-Aided Molecular Design 17, $755-763$.

Caumartin Y, Stephen J, Deng JP, Lian D, Lan Z, Liu W, Garcia B, Javnikar AM, Wang H, Cepinskas G, Luke PPW (2011) Kidney International 79(10): 1080-1089.

Chakraborty I, Carrington SJ, Mascharak PK (2014) ChemMedChem 9(6): 1266-1274.

Chlopicki S, Lomnicka M, Federowicz A, Grochal E, Kramkowski K, Mogielnicki A, Buczko W, Motterlini R (2012) Naunyn-Schmiedeberg's Archives of Pharmacology 385: 641-650.

Clark JE, Naughton P, Shurey S, Green CJ, Johnson TR, Mann BE, Foresti R, Motterlini R (2003) Circulation Research 93: e2-e8.

Farrugia G, Szurszewski JH (2014) Gastroenterology 147(2): 303-313.

Foresti R, Hammad J, Clark JE, Johnson TR, Mann BE, Friebe A, Green CJ (2004) British Journal of Pharmacology 142(3): 453-460.

Foresti R, Bani-Hani MG, Motterlini R (2008) Intensive Care Medicine 34: 649-658.

Govender P, Pai S, Schatzschneider U, Smith GS (2013) Inorganic Chemistry 52(9): 5470-5478.

Hartl F, Rosa P, Ricard L, Le Floch P, Záliš (2007) Coordination Chemistry Reviews 251(3-4): 557-576.

Hasegawa U, Van Der Vlies AJ, Simeoni E, Wandrey C, Hubbell JA (2010) Journal of the American Chemical Society 132: 18273.

Huber W, Linder R, Niesel J, Schatzschneider U, Spingler B, Kunz PC (2012) European Journal of Inorganic Chemistry 19: 3140-3146.

Ji X, Damera K, Zheng Y, Yu B, Otterbein LE, Wang B (2016) Journal of Pharmaceutical Sciences 105(2): 406-416.

Johnson TR, Mann BE, Clark JE, Foresti R, Green CJ, Motterlini R (2003) Angewandte Chemie International Edition 42(32): 3722-3729.

Johnson TR, Mann BE, Teasdale IP, Adams H, Foresti R, Green CJ, Motterlini R (2007) Dalton Transaction 15: 1500-1508.

Kimberly L, La Cruz CD, Pan Z, Chittavong V, Wang B (2017) Chemical Communications 53: 9628-9631.

Koopmans T (1934) Physica 1: 104-113.

Lamon BD, Zhang FF, Puri N, Brodsky SV, Goligorsky MS, Nasjletti A (2009) Circulation Research 105: 775-783.

Mann BE (2012) Organometallics 31(16): 5728-5735.

Mann BE, Motterlini R (2007) Chemical Communications 4197-4208.

Mansour AM, Ragab MS (2019) Applied Organometallic Chemistry 3(7): e4944.

Morris GM, Goodsell DS, Halliday RS, Huey R, Hart WE, Belew RK, Olson AJ (1999) Journal of Computational Chemistry 19(14): 1639-1662. 
Morris GM, Huey R, Lindstrom W, Sanner MF, Belew RK, Goodsell DS, Olson AJ (2009) Journal Computational Chemistry 30(16): 2785-2791.

Motterlini R, Clark JE, Foresti R, Sarathchandra P, Mann BE, Green CJ (2002) Circulation Research 90: e17-e24.

Motterlini R, Mann BE, Foresti R (2005) Expert Opinion on Investigational Drugs 14(11): 1305-1318.

Motterlini R, Otterbein LE (2010) Nature Reviews Drug Discovery 9: 728-743.

Motterlini R, Sawle P, Bains S, Hammad J, Alberto R, Foresti R, Green CJ (2005) FASEB Journal 19(2): 1-24.

Neese F (2006) Journal of Biological Inorganic Chemistry 11: 702-711.

Neese F (2009) Coordination Chemistry Reviews 253(5-6): 526-563.

Neese F (2012) Wiley Interdisciplinary Reviews: Computational Molecular Science 2(1): 73-78.

Niesel J, Pinto A, N'Dongo HWP, Merz K, Ott I, Gust R, Schatzschneider U (2008) Chemical Communications (ChemComm) 15: 1798-1800.

Özdemir İ, Çiftçi O, Evren E, Gürbüz N, Kaloğlu N, Türkmen NB, Yaşar Ş, Üstün E, Hamdi N, Mansour L, Özdemir İ (2020) Inorganica Chimica Acta 506 : 119530.

Pfeiffer H, Sowik T, Schatzschneider U (2013) Journal of Organometallic Chemistry 734: 17-24.

Romão CC, Blättler WA, Seixas JD, Bernardes GJL (2012) Chemical Society Reviews 41: 3571-3583.

Roy RK, Krishnamurti S, Geerlings P, Pal S (1998) The Journal of Physical Chemistry A 102(21): 3746-3755.
Ryan MJ, Jernigan NL, Drummond HA, McLemore GR, Rimoldi JM, Poreddy SR, Gadepalli RSV, Stec DE (2006) Pharmacological Research 54(1): 24-29.

Ryter SW, Otterbein LE (2004) BioEssays 26(3): 270-280.

Serdaroğlu G, Şahin N (2019) Journal of Molecular Structure 1178: 212-221.

Singh UC, Kollman PA (1984) Journal of Computational Chemistry 5(2): 129-145.

Smith H, Mann BE, Motterlini R, Poole RK (2011) IUBMB Life 63(5): 363-371.

Tenhunen R, Marver HS, Schmid R (1968) Proceedings of the National Academy of Sciences 61(2): 748-755.

Tian Z, Zang F, Luo W, Zhao Z, Wang Y, Xu X, Wang C (2015) Journal of Photochemistry and Photobiology B: Biology 142: 103-109.

Üstün E, Çelebi MS, Ayvaz MÇ (2018) Journal of Coordination Chemistry 71(16-18): 2978-2992.

Üstün E, Düşünceli SD, Özdemir İ (2019) Structural Chemistry 30: 769-775.

Üstün E, Koç Ş, Demir S, Özdemir İ (2016) Journal of Organometallic Chemistry 815-816: 16-22.

Varma RR, Pandya JG, Vaidya FU, Pathak C, Bhatt BS, Patel MN (2020) Chemico-Biological Interactions 330: 109231.

Weigend F, Ahlrichs R (2005) Physical Chemistry Chemical Physics 7: 3297-3305.

Winburn IC, Gunatunga K, McKernan RD, Walker RJ, Sammut IA, Harrison JC (2012) Basic \& Clinical Pharmacology \& Toxicology 111(1): 31-41.

Wu L, Wang RUI (2005) Pharmacological Reviews 57(4): $585-630$. 